\title{
E3 Ubiquitin-Protein Ligase HACE1
}

National Cancer Institute

\section{Source}

National Cancer Institute. E3 Ubiquitin-Protein Ligase HACE1. NCI Thesaurus. Code C119639.

E3 ubiquitin-protein ligase HACE1 (909 aa, 102 kDa) is encoded by the human HACE1 gene. This protein is involved in the regulation of both the ubiquitination and subsequent degradation of small GT Pases, which modulates Golgi membrane dynamics. 